\title{
Fattening pig performance as affected by the number of pigs per pen, the bedded surface area and the available volume per pig in fattening houses with partial slatted floor
}

\author{
C. TEXIER *, A. BOUBY**, Y. CANTALOUBE ** \\ Institut Technique du Porc \\ *149, rue de Bercy, 75595 Paris Cedex 12 \\ *: Station Expérimentale, 12200 Villefranche-de-Rouergue
}

Despite numerous studies on housing of fattening pigs, some questions have not yet been elucidated : How many pigs per pen? How large the area and useful volume per pig? How many pigs per house? Is it possible to cram the fattening pens?

A total of 12 trials were made by the I.T.P. $(*)$ over a 3-year period (from August 1979 to June 1982). The following conclusions were drawn :

- Whatever the feeding restriction applied (restricted castrated males or ad libitum females), growth differences observed between 65 and $100 \mathrm{~kg}$ live weight in groups of 10-15 or 20 pigs per pen were not significant. (In castrated males the daily mean gain was 657-612 and $615 \mathrm{~g}$, respectively and in females it was $665-673$ and $726 \mathrm{~g}$ in spring, 693-707 and 733 or $783-814$ and $804 \mathrm{~g}$ in autumn).

- Reduction of the bedded area per pig $\left(60-55\right.$ and $\left.50 \mathrm{~cm}^{2}\right)$ significantly improved the daily mean gain during late fattening in restricted castrated males (728-849 and $825 \mathrm{~g})$ as well as in ad libitum females (717-831 and $826 \mathrm{~g}$ ) in autumn. In spring, no difference was significant (696-696 and 639 or $732-706$ and $700 \mathrm{~g}$, respectively).

- The available volume per pig $\left(3-4\right.$ or $\left.6 \mathrm{~m}^{2}\right)$ and the capacity of the fattening room (40 or 80 places) had no effect on the growth of animals subjected to static ventilation.

- Daily mean gain decreased from $60 \mathrm{~kg}$ live weight as soon as the pen cramming reached or exceeded 20 p. $100(716,681,680$ and $673 \mathrm{~g}$ in restricted castrated males and $751,723,711$ and $694 \mathrm{~g}$ in restricted females also when the number of pigs per pen was 9-10-11 and 12 , respectively).

\section{Influence of restricted space on performance and behaviour of pigs in growing-finishing period}

\author{
Marie-Christine MEUNIER-SALAÜN, Marie-Noëlle VANTRIMPONTE \\ I.N.R.A., Station de Recherches sur l'Elevage des Porcs, \\ Saint-Gilles, 35590 L'Hermitage
}

The effect of restricted space for growing-finishing $25-100 \mathrm{~kg}$ pigs was studied for resting area. Three treatments i.e. $0.34-0.68-1.01 \mathrm{~m}^{2}$ of bedded area available per pig between 30 and $100 \mathrm{~kg}$ of live weight were compared in groups of eight animals (four castrated males and four females). Five replicates of 8 pigs per treatment were used.

(*) Institut Technique du Porc. 
According to the space allowance proposed by PETHERICK (1983) from a weight of $60 \mathrm{~kg}$ all animals could not rest on their sternum at the same time : $0.34 \mathrm{~m}^{2} / \mathrm{pig}$, or fully recumbent : $0.68 \mathrm{~m}^{2} / \mathrm{pig}$ from a weight of $60-70 \mathrm{~kg}$, or no space restriction : $1.01 \mathrm{~m}^{2} / \mathrm{pig}$. Production performance was deteriorated in pigs allowed only $0.34 \mathrm{~m}^{2} / \mathrm{pig}$ perceptible from 10 weeks following the beginning of the experiment $(70-80 \mathrm{~kg})$ and until slaughter i.e. 5 to 16 p. 100 : daily gain; 7 to 14 p. 100 : feed efficiency.

Behavioural observations in spontaneous situation and space restriction of $0.34 \mathrm{~m} \% / \mathrm{pig}$ showed a larger individual time spent at the trough in relation with a monopolization by four animals. During a 24-h cycle, resting behaviour was expressed more in sternum position when live weight reached $60 \mathrm{~kg}$. In addition, social and playing behaviour were a little reduced. No difference was observed between the two treatments : $0.68 \mathrm{~m}^{2} / \mathrm{pig}$ and $1.01 \mathrm{~m}^{2} /$ pig. Animals did not exhibit an abnormal behaviour (tail biting, belly nosing) in any of the three treatments.

In conclusion, a severe restriction did not increase the aggressivity, but induced a "social avoidance» between animals. Even though adaptative capacities of the growing pig were observed, differences between treatment tended to show an alteration of the behaviour of animals from 8 weeks after the beginning of the experiment $(50-60 \mathrm{~kg}$ ), whereas no trouble appeared in weight performance. Behaviour parameters such as feeding, resting, spatial behaviour and social relationships appeared to be more sensitive and more early indicators of disturbance than growth performance.

\title{
Pig house exhibition and testing centre in Trevarez (France)
}

\author{
J. CALLAREC \\ Etablissement Départemental de l'Elevage du Finistère, \\ 3, allée Sully, B.P. 504, 29109 Quimper Cedex
}

The first characteristic of the pighouse exhibition and testing centre in Trevarez is to be designed by and for people responsible for popularization, E.D.E. (*) and chambers of Agriculture of Brittany with the support of the I.T.P. $\left(^{*}\right)$ of Rennes. It is not a centre of research on pig housing, but an exhibition centre of the different models of piggeries designed and managed according to the recently defined pig environmental requirements, especially temperature.

The following models are exhibited :

- 11 models of fattening piggeries - for 810 individuals;

- 3 models of boar-pregnant sows houses - for 24 sows and 3 boars;

- 3 farrowing houses - for 9 individuals ;

- 3 models of post-weaning houses - for 180 individuals.

Moreover, equipment for inner arrangement, ventilation and heating are exhibited and building techniques are displayed.

Performances are measured in each piggery. It may be concluded after three years of operation that fattening results are very similar from one model to another.

(*) E.D.E. : Etablissement Départemental de l'Elevage du Finistère.

(*) I.T.P. : Institut Technique du Porc. 